\title{
Correlation between Semaphorin3A-Induced Facilitation of Axonal Transport and Local Activation of a Translation Initiation Factor Eukaryotic Translation Initiation Factor 4E
}

\author{
Chanxia Li, ${ }^{1}$ Yukio Sasaki, ${ }^{1}$ Kohtaro Takei, ${ }^{1,4}$ Hiroshi Yamamoto, ${ }^{1}$ Masayuki Shouji, ${ }^{1}$ Yoshinobu Sugiyama, ${ }^{1}$ \\ Tadashi Kawakami, ${ }^{2}$ Fumio Nakamura, ${ }^{1}$ Takeshi Yagi, ${ }^{3}$ Toshio Ohshima, ${ }^{4}$ and Yoshio Goshima ${ }^{1,5}$ \\ ${ }^{1}$ Department of Molecular Pharmacology and Neurobiology, Yokohama City University Graduate School of Medicine, Yokohama 236-0004, Japan, \\ ${ }^{2}$ Department of Physiology, Kitasato University School of Medicine, Sagamihara 228-8555, Japan, ${ }^{3}$ Division of Molecular Genetics, Section of Gene \\ Networks and Gene Functions, Institute for Molecular and Cellular Biology, Osaka University, Suita 565-0871, Japan, ${ }^{4}$ Laboratory for Developmental \\ Neurobiology, Brain Science Institute, The Institute of Physical and Chemical Research, Wako 351-0198, Japan, and ${ }^{5}$ Core Research for Evolutional Science \\ and Technology, Japan Science and Technology Corporation, Kawaguchi 332-0012, Japan
}

An impressive body of evidence has been accumulated indicating that local protein synthesis is implicated in navigation of neurite extension induced by guidance cues, such as semaphorin3A (Sema3A). We found previously that a Src type tyrosine kinase Fyn and cyclin-dependent kinase 5 (Cdk5) mediate Sema3A-signaling. We also showed that Sema3A elicits axonal transport through neuropilin-1, a receptor for Sema3A, located at the growth cones. Here, we investigate the relationship between Sema3A-induced local signaling, protein synthesis, and axonal transport. Lavendustin A, a tyrosine kinase inhibitor, and olomoucine, a cyclin-dependent kinase inhibitor, suppressed Sema3A-induced facilitation of anterograde and retrograde axonal transport in dorsal root ganglion (DRG) neuron with and without the cell body. Sema3A-induced facilitation of axonal transport was attenuated in DRG neurons of fyn- ( fyn $\left.{ }^{-/-}\right)$and a Cdk5 activator, $p 35\left(p 35^{-1-}\right)$-deficient mice when compared with those of wild-type or heterozygous mice. Inhibition of protein synthesis suppressed Sema3A-induced facilitation of axonal transport in the DRG neuron with and without the cell body. Sema3A enhanced the level of immunoreactivity of phosphorylated eukaryotic translation initiation factor $4 \mathrm{E}$ (eIF-4E) within 5 min in growth cones in a time course similar to that of the facilitated axonal transport. This enhanced signal for phospho-eIF4E was blocked by lavendustin A or olomoucine and was not detected in the $f y n^{-/-}$and $p 35^{-/-}$neurons. These results provide evidence for a mutual regulatory mechanism between local protein synthesis and axonal transport.

Key words: axon guidance; Sema3A; Fyn; Cdk5; axonal transport; growth cones; local protein synthesis

\section{Introduction}

For the wiring of individual neurons together into an orderly network, the establishment and maintenance of their asymmetry is a critical event, and molecular components destined for specific subcellular domains of a neuron must be targeted correctly. Axonal transport plays a crucial role in these processes. However, the molecular mechanisms underlying the regulation of axonal transport during the axon guidance process remain mostly unknown. Four types of axon guidance cues, attractive and repulsive cues control neuronal extension and navigation to their targets

Received Dec. 4, 2003; revised May 17, 2004; accepted May 17, 2004.

This work was supported by grants-in-aid from the Ministry of Education, Culture, Sport, Science, and Technology of Japan (Y.S.), Core Research for Evolutional Science and Technology of Japan Science and Technology Corporation (K.T. and Y.G.), and the Uehara Memorial Foundation (Y.G.). We are grateful to Drs. H. Hiruma and H. Hori for helpful discussions. C.L. is especially grateful to M. Katatani-Furuse, who died of cancer on May 20, 1999, for providing financial support. We dedicate this study to her memory.

Correspondence should be addressed to Y. Goshima, Department of Molecular Pharmacology and Neurobiology, Yokohama City University Graduate School of Medicine, Yokohama 236-0004, Japan. E-mail: goshima@med.yokohama-cu.ac.jp.

D0I:10.1523/JNEUROSCI.1476-04.2004

Copyright $\odot 2004$ Society for Neuroscience $\quad 0270-6474 / 04 / 246161-10 \$ 15.00 / 0$
(Tessier-Lavigne and Goodman, 1996). Accurate navigation by a neuronal growth cone requires the modulation of the responsiveness of the growth cone to spatial and temporal changes in the expression of these guidance cues. In these processes, localized protein synthesis and proteolysis are required for growth cone repulsive and attractive responses, alteration of responsiveness of axons to guidance cues (i.e., desensitization), resensitization, and upregulated cell surface protein expression of distal axon segments (Campbell and Holt, 2001, 2003; Brittis et al., 2002; Gallo and Letourneau, 2002; Ming et al., 2002).

Semaphorin3A (Sema3A), a secreted type of guidance cue of the semaphorin family, possesses a strong repulsive activity to dorsal root ganglia (DRG) and sympathetic neurons. Sema3A regulates actin dynamics via phosphorylation of cofilin by LIM (Lin-11, Isl-1, and Mec-3) kinases (Aizawa et al., 2001). We have reported that the Fyn-Cdk5 complex acts as a downstream mediator of Sema3A signaling cascades that induce growth cone collapse (Sasaki et al., 2002). Sema3A induces phosphorylation of tau, a microtubule-associated protein, through Cdk5, the activity of which requires a neuron-specific regulatory subunit p35 (Lew and Wang, 1995). Sema3A signaling is thus considered to be 
associated with both actin and microtubule reorganizations (Goshima et al., 2002). Because microtubule is the basic component for axonal transport, we sought to determine whether Sema3A has some effects on axonal transport. By using a videoenhanced contrast differential interference video camera system, we found that Sema3A induces anterograde and retrograde fast axonal transport (Goshima et al., 1997, 1999). Axonal transport as well as growth cone collapse elicited by Sema3A are blocked either by ecto-domain of neuropilin-1 (NRP-1), the binding receptor unit for Sema3A, or by functional blocking antibody against NRP-1, indicating that both the responses are mediated by NRP-1. The site of action of Sema3A is confined to the growth cone area, because the local application of Sema3A to the growth cone but not elsewhere induces both growth cone collapse and facilitation of axonal transport. This suggests that NRP-1 localized in the growth cone mediates the facilitatory action of Sema3A on anterograde and retrograde axonal transport (Goshima et al., 1999). However, mechanism and physiological relevance of the local regulation of axonal transport by Sema3A remain to be clarified.

Here, we report that local signaling elicited by Sema3A mediated the local activation of translation initiation factor in growth cones, and this was involved in Sema3A-induced facilitation of anterograde and retrograde axonal transport. Our present findings provide evidence that both local protein synthesis and axonal transport are involved mutually in Sema3A-induced responses. This could have some relevance in dynamic regulation of growth cone responsiveness to axon guidance molecules (Campbell and Holt, 2001; Brittis et al., 2002; Ming et al., 2002).

\section{Materials and Methods}

Materials. Plastic or glass eight-well chamber slides (slides) were from Nalgen International (Naperville, IL). Other glass products were purchased from Matsunami (Osaka, Japan). Collagenase type III was obtained from Worthington Biochemical (Lakewood, NJ). Lavendustin A was from Calbiochem (La Jolla, CA). Olomoucine, anisomycin, cycloheximide, $N$-Acetyl-Leu-Leu-NorLeu-Al (LnLL), trypsin, trypsin inhibitor, poly-L-lysine, and laminin were from Sigma (St. Louis, MO), and Percoll was from Amersham Biosciences (Uppsala, Sweden). Rabbit antimouse phospho-eukaryotic translation initiation factor 4E (eIF-4E) (Ser209) was obtained from Cell Signaling Technology (Beverly, MA). Alexa 594-labeled goat anti-rabbit antibody and Alexa fluorescein isothiocyanate-labeled phalloidine were purchased from Molecular Probes (Eugene, OR). Other reagents were purchased from Wako (Osaka, Japan) unless otherwise indicated.

Recombinant Sema3A. Recombinant Sema3A was prepared as described previously (Goshima et al., 1997; Nakamura et al., 1998). Conditioned medium containing Sema3A was collected 3-5 d after transfection and was applied to Talon (Clontech, Palo Alto, CA) column according to the instructions of the manufacturer. The column was washed with 20 mM Tris- $\mathrm{HCl}, \mathrm{pH}$ 8.0, buffer containing $0.5 \mathrm{M} \mathrm{NaCl}$. The recombinant Sema3A was eluted primarily in the $50 \mathrm{~mm}$ imidazole fraction. Conditioned medium of human embryonic kidney 293T cells transfected with the empty vector DNA was processed in parallel, and the column fraction with $50 \mathrm{~mm}$ imidazole was used as a control.

fyn- and p35- mutant mice. The fyn- and p35-deficient mice were generated as described previously (Yagi et al., 1993; Ohshima et al., 2001). Genotypes of the mutant animal offspring were assessed using PCR. Mice were housed in the standard mouse facility and fed with autoclaved diet and water. All procedures were performed according to the guidelines outlined by the Institutional Animal Care and Use Committee of the Yokohama City University Graduate School of Medicine. Throughout the experimental procedures, all efforts were made to minimize the number of animals used and their suffering.

Dissociated culture of adult mouse DRG. Dissociated neurons of DRG from adult (6-8 weeks of age) C57BL/6 mice (Japan SLC, Hamamatsu,
Shizuoka, Japan) for video recording of axonal transport along axon were prepared as described previously (Goshima et al., 1997). We used adult mouse DRG, because it was relatively easy to obtain a clear-cut image of moving organellae along the axons on video recording in adult mouse than embryonic DRG. In brief, DRG were incubated at $37^{\circ} \mathrm{C}$ for $90 \mathrm{~min}$ in Ham's F-12 medium (15 mm HEPES, 7.5 mм NaOH, 14 mм NaHCO 3 , $100 \mathrm{u} / \mathrm{ml}$ penicillin, $100 \mu \mathrm{g} / \mathrm{ml}$ streptomycin, $\mathrm{pH}$ 7.4) containing 2.5 $\mathrm{mg} / \mathrm{ml}$ collagenase. Thereafter, the ganglia were incubated at $37^{\circ} \mathrm{C}$ for 15 min in HBSS containing $2.5 \mathrm{mg} / \mathrm{ml}$ trypsin. Trypsinization was stopped by addition of $0.12 \mathrm{mg} / \mathrm{ml}$ trypsin inhibitor. Dissociated cells were obtained by triturating the ganglia through fire-polished glass Pasteur pipettes with an inner diameter of $0.3-0.4 \mathrm{~mm}$. The cells were then dropped onto a $5 \mathrm{ml}$ cushion of $30 \%$ Percoll in HBSS and centrifuged at $400 \times g$ for $5 \mathrm{~min}$. The purified neurons were plated onto poly-L-lysine $(10 \mu \mathrm{g} / \mathrm{ml})$-coated glass microslips $(30 \times 40 \mathrm{~mm})$ and were cultured with Ham's F12 medium containing $10 \mathrm{ng} / \mathrm{ml} \mathrm{NGF}$ and $10 \% \mathrm{FBS}$ at $37^{\circ} \mathrm{C}$ in a $5 \% \mathrm{CO}_{2}-95 \%$ air-containing incubator.

Video-enhanced microscopy. After a $48 \mathrm{hr}$ period of culture, the cover glasses were attached with waterproof tape to the underside of a $0.5 \mathrm{~mm}$ thick stainless-steel plate $(40 \times 75 \mathrm{~mm})$ with a lozenge-shaped hollow $(14 \times 18 \mathrm{~mm})$. The top side of the steel plate was covered with a $30 \times 30$ $\mathrm{mm}$ cover glass, leaving a small opening on both sides to perfuse solution through. The hollow space between the two glass covers was filled with physiological salt solution (PSS) containing $135 \mathrm{~mm} \mathrm{NaCl}, 5 \mathrm{~mm} \mathrm{KCl}, 1$ $\mathrm{mM} \mathrm{MgCl}_{2}, 5.5 \mathrm{~mm}$ D-glucose, $15 \mathrm{~mm}$ HEPES, and $7.5 \mathrm{~mm} \mathrm{NaOH}, \mathrm{pH} 7.4$ $\left(37^{\circ} \mathrm{C}\right)$ as described previously (Goshima et al., 1999). The plates were placed on an inverted Axiomat microscope with an oil-immersed planApochromat $63 \times$ NA 1.4 (Oil DIC) objective lens (Zeiss, Thornwood, $\mathrm{NY}$ ) equipped with an Allen video-enhanced contrast differential interference contrast (AVEC-DIC) video camera (Hamamatsu Photonics, Shizuoka, Japan). The stage was maintained at $37^{\circ} \mathrm{C}$ by using a temperature controller. For quantification of the motility of the organelles, a line perpendicular to the long axis of the axon was drawn on the video monitor, and the number of moving organelles crossing the line was successively counted for every $2 \mathrm{~min}$ at intervals of $1 \mathrm{~min}$ throughout the experiments as described previously (Goshima et al., 1997). Solution between the cover glasses was replaced with $1.5 \mathrm{ml}$ of the PSS buffer containing Sema3A, and thereafter Sema3A was present throughout the experiments. When the effects of inhibitors were tested, PSS containing each of these agents was applied $7 \mathrm{~min}$ before addition of Sema3A and was present throughout the experiments. Nomarski time-lapse images were displayed on a video monitor and were stored on a video recorder (U-matic SP videocassette; Sony, Tokyo, Japan).

Preparation of isolated axons. The isolated axons were prepared from dissociated DRG cultured for $48 \mathrm{hr}$ on poly-L-lysine $(10 \mu \mathrm{g} / \mathrm{ml})$-coated cover glasses. The somas of neurons were taken off by using a sterile glass needle under a light microscopy. The cover glasses were immediately mounted onto the plates as described above. The spaces between the cover glasses were filled with L-15 medium containing $25 \mathrm{~mm}$ glucose preincubated at $37^{\circ} \mathrm{C}$. The plates were then set onto the stage of AVECDIC video camera, and the recording of moving particles in the isolated axons was started $30 \mathrm{~min}$ after the removal of the cell soma.

Adult mouse DRG explant culture. For immunostaining and collapse assay in DRG, we developed a method for preparing explant culture from adult mouse DRG to match the age of mice used for analysis of axonal transport (see above). The DRG was sliced into several pieces by a razor. The slices were transferred to Ham's F-12 medium containing $2.5 \mathrm{mg} / \mathrm{ml}$ collagenase and incubated at $37^{\circ} \mathrm{C}$ for $90 \mathrm{~min}$ and thereafter in HBSS containing $3 \mathrm{mg} / \mathrm{ml}$ trypsin for $5-8 \mathrm{~min}$. Trypsinization was stopped by addition of $0.15 \mathrm{mg} / \mathrm{ml}$ trypsin inhibitor. The slices for explant culture were plated on the slides coated with poly-L-lysine $(30 \mu \mathrm{g} / \mathrm{ml})$ in $0.15 \mathrm{M}$ sodium borate, $\mathrm{pH} 8.5$, and laminin $(20 \mu \mathrm{g} / \mathrm{ml})$ and were incubated in Ham's F-12 medium containing $100 \mathrm{ng} / \mathrm{ml} \mathrm{NGF}$ and 10\% FBS.

Immunocytochemistry. DRG explants prepared as described above were cultured for $48 \mathrm{hr}$. Sema3A was applied to the medium, and some reagents, when used, were similarly applied $7 \mathrm{~min}$ before Sema3A. After a certain period of incubation time, cultures were then immersed with $4 \%$ paraformaldehyde in $20 \%$ sucrose-containing PBS $(137 \mathrm{~mm} \mathrm{NaCl}$, $8.1 \mathrm{~mm} \mathrm{Na}_{2} \mathrm{HPO}_{4}, 2.68 \mathrm{~mm} \mathrm{KCl}, 1.47 \mathrm{~mm} \mathrm{KH}_{2} \mathrm{PO}_{4}$, pH 7.4) for $30 \mathrm{~min}$. 
Explants were washed once with PBS and permeated with $0.3 \%$ Triton X-100 in PBS for $2 \mathrm{~min}$. Samples were washed three times each for $5 \mathrm{~min}$ with PBS containing $0.1 \%$ Triton X-100 (wash buffer). Explants were rinsed with the washing buffer once and incubated with blocking buffer ( $5 \%$ goat serum, $1 \%$ BSA in washing buffer) for $1 \mathrm{hr}$. Cultures were rinsed once in washing buffer for $5 \mathrm{~min}$ and then incubated overnight at $4^{\circ} \mathrm{C}$ with primary antibodies diluted in blocking buffer without goat serum. eIF-4E phosphorylated at Ser209 was detected in DRG explant culture using anti-phospho-eIF-4E antibody (1:100). Samples were rinsed three times in washing buffer, each for $5 \mathrm{~min}$, followed by incubation with Alexa 594-labeled goat anti-rabbit antibody (1:1000). They were then mounted with Vectashield (Vector Laboratories, Burlingame, CA). To obtain quantitative measurements of immunofluorescence, the slides were placed on laser scanning microscope (LSM 510) with a waterimmersed objective at $40 \times(\mathrm{C}$-Apochromat $40 \times 1.2 \mathrm{~W}$ Korr $)$ equipped with Axioplan 2 imaging microscope (Zeiss). Growth cones were randomly selected and the images captured. The outline was traced and the intensity of fluorescence within the growth cone area was measured with background subtraction as described previously (Cheng et al., 2003).

Statistics of significance. Data are shown as mean \pm SEM. The statistical significance of the results was analyzed using the Mann-Whitney nonparametric test.

\section{Results}

Inhibitors of tyrosine kinases and cyclin-dependent kinases suppress Sema3A-induced axonal transport in adult mouse DRG

To test the possibility that Fyn and Cdk5 mediate Sema3Ainduced axonal transport as well as growth cone collapse (Sasaki

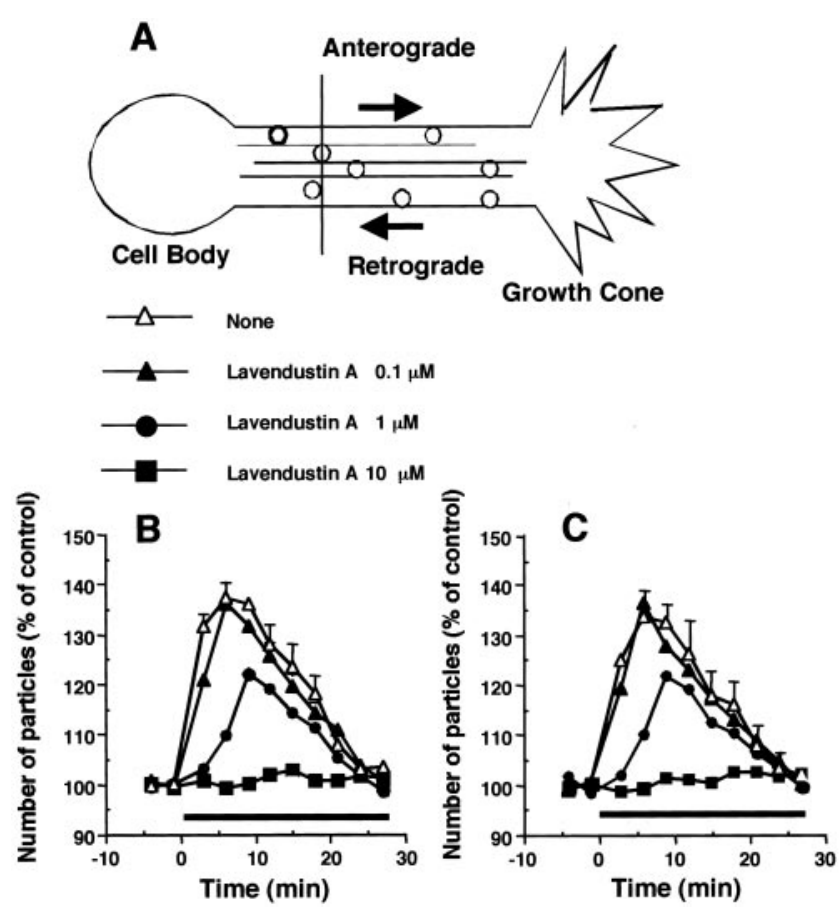

Figure 1. A, Schematic diagram of analysis for axonal transport. Moving particles were monitored by AVEC-DIC system, and the number of particles per minute crossing the line (vertical line) was counted on the display. Lavendustin A concentration dependently inhibited Sema3A-induced facilitation of anterograde $(B)$ and retrograde $(C)$ axonal transport in dissociated neurons of adult mouse DRG. Sema3A ( $5 \mathrm{~nm}$ ) was applied at 0 min and thereafter present throughout the experiments (horizontal bar). Lavendustin A was applied at 7 min before the application of Sema3A and was present throughout the experiments. Ordinates show the percentage changes of control in the number of moving particles calculated from the average of the two values before application of Sema3A. Horizontal axes show the time after Sema3A application. Data shown are mean $\pm \operatorname{SEM}(n=5) . n$ is the number of independent experiments performed.
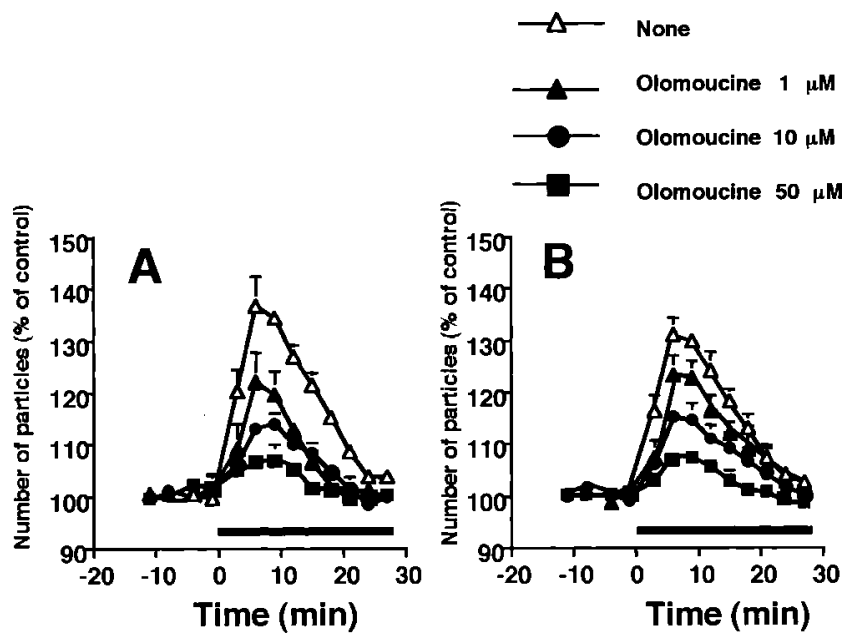

Figure 2. Inhibition by olomoucine against Sema3A-induced facilitation of axonal transport. $A, B$, Olomoucine concentration dependently inhibited Sema3A-induced facilitation of anterograde $(A)$ and retrograde $(B)$ axonal transport. Data shown are mean \pm SEM $(n=$ 5-10). Other details are as in Figure 1 and this study.

et al., 2002), we examined the effects of lavendustin A and olomoucine on axonal transport in the adult mouse DRG. Control basal absolute values of the number of particles for anterograde and retrograde axonal transport (per minute) before application of Sema3A were $63 \pm 7$ and $66 \pm 7$ and showed almost equal number of moving particles in anterograde and retrograde axonal transport. Therefore, lavendustin A had no effect on the basal number of anterograde and retrograde moving particle per minute in the axon. This indicates that lavendustin A-sensitive tyrosine kinase(s) was not involved in the mechanism regulating basal axonal transport. After exposure to Sema3A, the levels of anterograde and retrograde axonal transport started to increase within 2-3 min, and their peaks were seen at $6 \mathrm{~min}$ (Fig. $1 B, C$ ). Pretreatment with lavendustin A $(0.1-10 \mu \mathrm{M})$ concentration dependently inhibited Sema3A (5 nM)-induced anterograde and retrograde axonal transport. Lavendustin A at 0.1 and $1 \mu \mathrm{M}$ affected the initial rise induced by Sema3 $\mathrm{A}$ in both anterograde and retrograde axonal transport. The peak effect of Sema3A was somewhat delayed by lavendustin A when compared with the corresponding control. The percentage inhibition by lavendustin A at $0.1,1$, and $10 \mu \mathrm{M}$ against the peak effect on anterograde axonal transport was 7, 52, and $100 \%$, respectively. On retrograde axonal transport, the inhibition by lavendustin $\mathrm{A}$ at $0.1,1$, and 10 $\mu \mathrm{M}$ was 4,38 , and $100 \%$, respectively.

Olomoucine alone at the concentrations tested showed no effect on the basal levels of moving particle in the axons. This suggests that olomoucine-sensitive kinases, including cyclindependent kinase(s) such as Cdk5, were not involved in the mechanism regulating basal axonal transport in cultured mouse DRG. Meanwhile, olomoucine (1-50 $\mu \mathrm{M})$ concentration dependently inhibited Sema3A (5 nM)-induced facilitation of anterograde and retrograde axonal transport (Fig. $2 A, B$ ). This is consistent with the finding that olomoucine inhibits growth cone collapse induced by Sema3A or another repulsive axon guidance molecule ephrin-A5 (Sasaki et al., 2002; Cheng et al., 2003). Olomoucine potentially inhibits erk-1 $\left(\mathrm{IC}_{50}=25 \mu \mathrm{M}\right)$ and mitogenactivated protein kinases (MAPKs) $(30 \mu \mathrm{M})$ as well as cdc2-like kinases (Meijer et al., 1997). However, the present study suggests that Cdk5, at least in part, mediated Sema3A-induced axonal transport, because the $\mathrm{IC}_{50}$ of olomoucine against Sema3A (5 

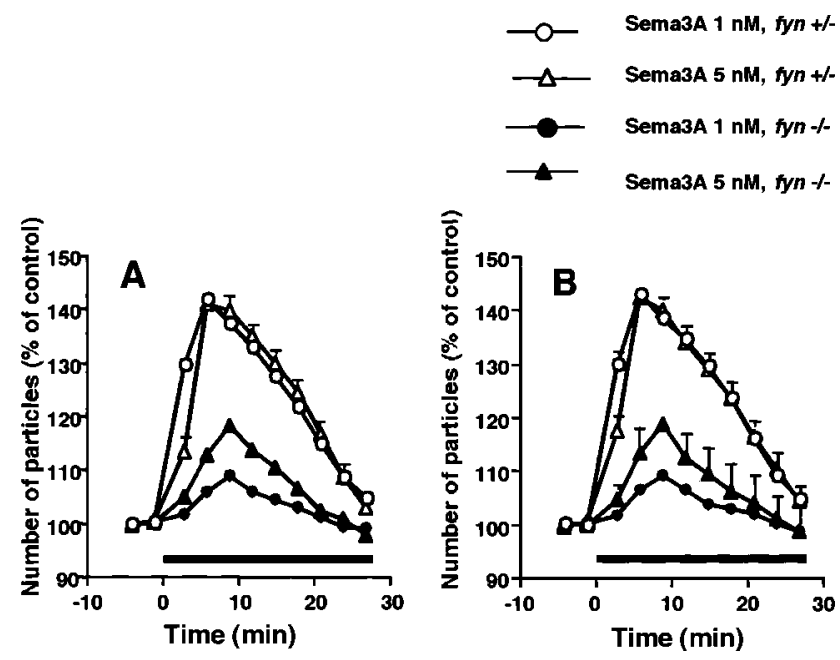

Figure 3. Sema3A-induced axonal transport was attenuated in adult fyn-homozygous $\left(\right.$ fyn $^{-1-}$ ) mouse DRG. $A, B$, The effects of Sema3A on anterograde $(A)$ and retrograde $(B)$ axonal transport in adult fyn ${ }^{-1-}$ and fyn ${ }^{+1-}$ DRG neurons are shown. Data shown are mean $\pm \operatorname{SEM}(n=8-15)$.

$\mathrm{nM}$ )-induced axonal transport was $<10 \mu \mathrm{M}$ on both anterograde and retrograde axonal transport (Fig. 2). In addition, our preliminary study shows that PD98059, a MAPK/extracellular signalregulated kinase kinase (MEK) at $10 \mu \mathrm{M}$ fails to affect Sema3Ainduced axonal transport (data not shown). It is also unlikely that cdc2 is responsible for Sema3A-induced axonal transport, because cdc2 is not detected in growth cones and axons of DRG using anti-Cdc2 antibody (Sasaki et al., 2002).

Sema3A-induced facilitation of axonal transport is attenuated in fyn- and $p 35$-deficient mouse DRG

To confirm involvement of Fyn and Cdk5 in mediating Sema3Ainduced axonal transport, we analyzed axonal transport in fyndeficient $\left(\mathrm{fyn}^{-/-}\right)$and $p 35$-deficient $\left(p 35^{-/-}\right)$mice DRG neurons. There were no differences in the basal number of anterograde and retrograde moving particles between $\mathrm{fyn}^{-/-}$, fyn ${ }^{+/-}, p 35^{-1-}$, and wild-type mouse DRG neurons (data not shown). Sema3A (1 and $5 \mathrm{~nm}$ )-induced increases in axonal transport of $f y n^{-1-}$ DRG neurons were lower when compared with those of $f y n^{+/-}$DRG neurons (Fig. $3 A, B$ ). The peak levels obtained with Sema3A at 1 and $5 \mathrm{nM}$ on anterograde transport in fyn $^{-1-}$ mouse DRG were 23 and $44 \%$ of corresponding peaks in $f y n^{+/-}$DRG, respectively. Such a difference in the responsiveness to Sema3A was similarly observed in the retrograde axonal transport: the peak effects of 1 and $5 \mathrm{~nm}$ Sema3A in $f \mathrm{yn}^{-1-}$ DRG were 22 and $43 \%$ of those in $f y n{ }^{+/-}$DRG, respectively (Fig. 3 ). The maximal effects of Sema3A on anterograde and retrograde axonal transport were similar in $f y n^{+/-}$and wild-type DRGs (Goshima et al., 1997, 1999).

We previously demonstrated that the growth cone collapse response to Sema3A is attenuated in embryonic DRG of $c d k 5$ deficient mice (Sasaki et al., 2002). However, we could not check the effect of Sema3A on axonal transport of the adult mouse DRG, because $c d k 5$-deficient mice are embryonic lethal (Ohshima et al., 1996). We therefore tested $p 35$-deficient mouse DRG, because this mutant strain can survive to viable adult animals (Ohshima et al., 2001). Consistently, Sema3A-induced growth cone collapse response was attenuated in $p 35^{-1-}$ DRG when compared with wild-type DRG (Fig. 4A) (Sasaki et al., 2002). In wild-type DRG, Sema3A (0.1-5 nM) rapidly facilitated antero-
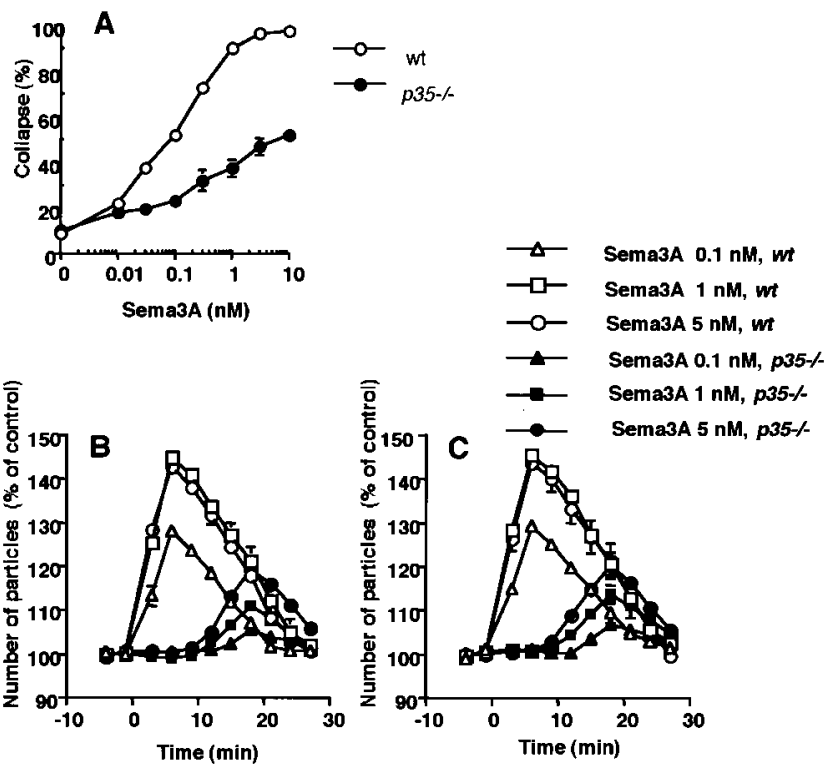

Figure 4. Sema3A-induced growth cone collapse and axonal transport were attenuated in p35 $\left(p 35^{-/-}\right)$mouse DRG. The effects of Sema3A on growth cone morphology $(A)$, anterograde $(B)$ and retrograde $\left(C\right.$ axonal transport in adult $p 35^{-/-}$, and wild-type (wt) DRG neurons are shown. An explant and dissociated cell culture of DRG were used for growth cone collapse assay and analysis of axonal transport, respectively. Data shown are mean \pm SEM $(n=5-8)$.

grade and retrograde axonal transport (Fig. $4 B, C$ ). In contrast, the initial rise in anterograde and retrograde axonal was suppressed in $p 35^{-1-}$ DRG (Fig. $4 B, C$ ), accompanied with delay of their peaks after Sema3A. This is somewhat at odds with our finding that olomoucine suppressed the Sema3A-induced bidirectional transport without affecting their time course (Fig. 2). Although the reason for this discrepancy is unknown, this might be at least in part attributable to specificity or permeability of the drug.

Inhibition of protein synthesis, but not protein degradation, suppresses Sema3A-induced facilitation of axonal transport Protein synthesis and degradation mediate turning responses to axon guidance molecules in Xenopus retinal neurons (Campbell and Holt, 2001). We tested the effect of inhibition of protein synthesis and degradation on Sema3A-induced growth cone collapse in explant cultures of adult mouse DRG. Anisomycin (Kang and Schuman, 1996), an inhibitor of protein synthesis, at 1 and 10 $\mu \mathrm{M}$ did not affect the maximal response induced by Sema3 A at the high concentration of $1 \mathrm{nM}$, whereas anisomycin at the concentration range around $\mathrm{EC}_{50}$ effectively suppressed the Sema3Ainduced response (Fig. 5A). Cycloheximide, another protein synthesis inhibitor, also inhibited Sema3A-induced growth cone collapse without affecting the maximal response to Sema3A (data not shown). The $\mathrm{EC}_{50}$ values for growth cone collapse induced by Sema3A alone, Sema3A combined with $1 \mu \mathrm{M}$ anisomycin, and Sema3A combined with $10 \mu \mathrm{M}$ anisomycin were $0.10 \pm 0.01$, $0.18 \pm 0.01$, and $0.19 \pm 0.01 \mathrm{nM}(n=5)$, respectively. Thus these protein synthesis inhibitors attenuated Sema3A-induced growth cone collapse response (Fig. 5A,B). However, these inhibitors showed only a little effect on Sema3A-induced growth cone collapse, and a concentration dependency of the effect of anisomycin was unclear (Fig. 5A). We tried to use anisomycin at the higher concentration, but it was found to cause growth cone collapse by itself (data not shown). Although the exact reasons for this discrepancy are unknown, these might be attributable to 

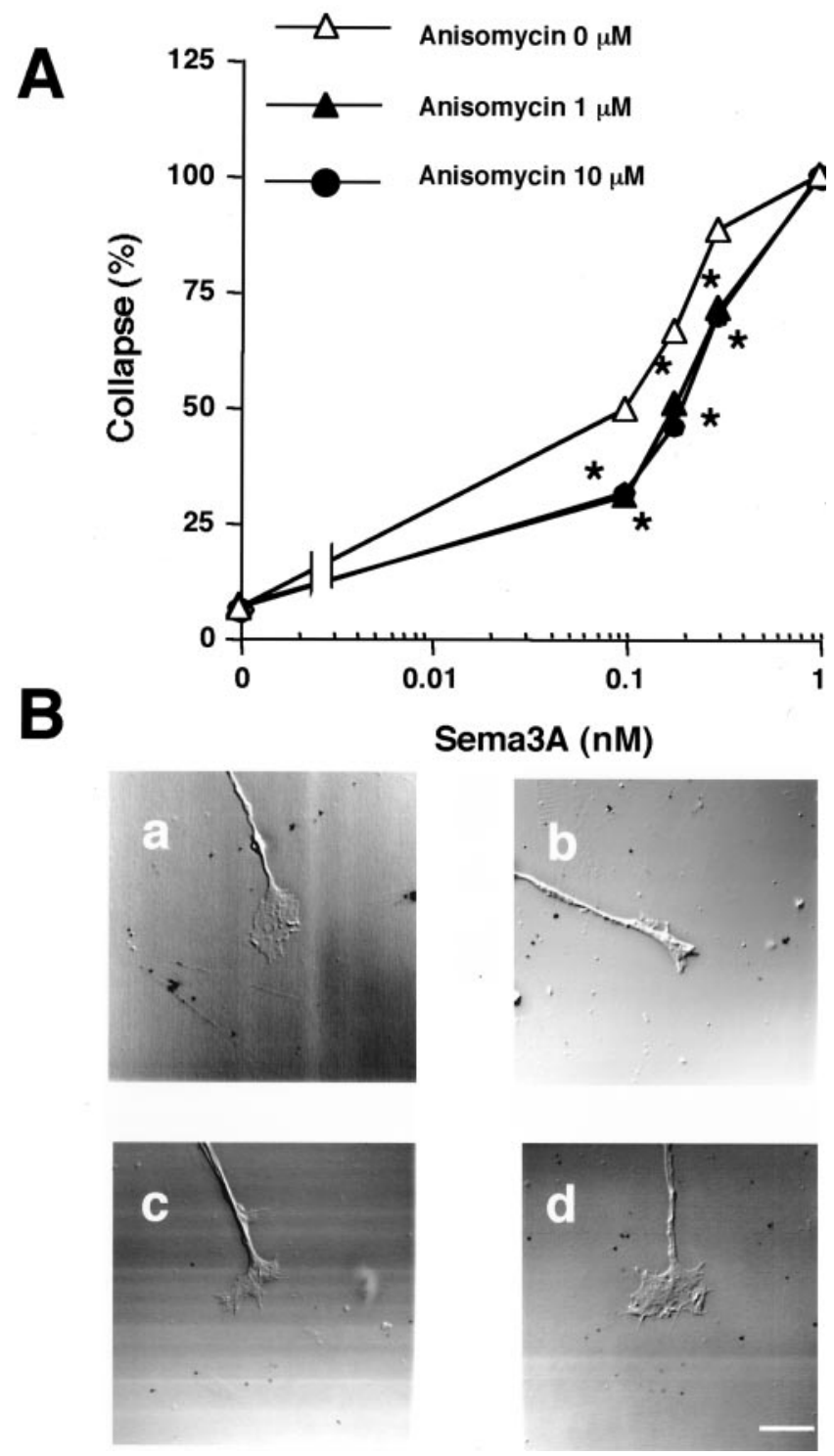

Figure 5. The effects of anisomycin on Sema3A-induced growth cone collapse in explant culture of adult mouse DRG. The DRG explants were treated with Sema3A for $30 \mathrm{~min}$. A, Anisomycin, applied 7 min before Sema 3 A, concentration dependently inhibited Sema3A-induced growth cone collapse but did not affect the maximal effect of Sema3A. Ordinates show the percentage collapse of growth cone induced by Sema3A. Data shown are mean $\pm \operatorname{SEM}(n=5)$. ${ }^{*} p<0.01$ compared with Sema3A alone. $B$, Morphological changes of growth cone $(a, b)$ and antagonism by anisomycin $(c, d)$ against the effect of Sema3A $0.1 \mathrm{~nm}(b, d)$. Scale bar, $10 \mu \mathrm{m}$.

species and other experimental conditions. For example, turning and collapse assay of Xenopus retinal neurons were performed in serum-free medium (Campbell and Holt, 2001, 2003). In contrast, the present study was performed using DRG neurons cultured in the presence of FBS and NGF. Together, we confirmed that inhibition of protein synthesis suppressed Sema3A-induced growth cone collapse (Campbell and Holt, 2001).

We next investigated a role of protein synthesis in Sema3Ainduced facilitation of axonal transport. Sema3A at $0.1-1 \mathrm{~nm}$ concentration dependently augmented anterograde and retrograde axonal transport (Fig. 6B,D). The maximal response of $\sim 50 \%$ over the basal control level was achieved at $1 \mathrm{~nm}$ Sema3 A on both anterograde and retrograde axonal transport. The $\mathrm{EC}_{50}$ value on Sema3A alone was $0.11 \pm 0.01 \mathrm{~nm}$ for anterograde transport and $0.13 \pm 0.01 \mathrm{nM}$ for retrograde transport, respectively
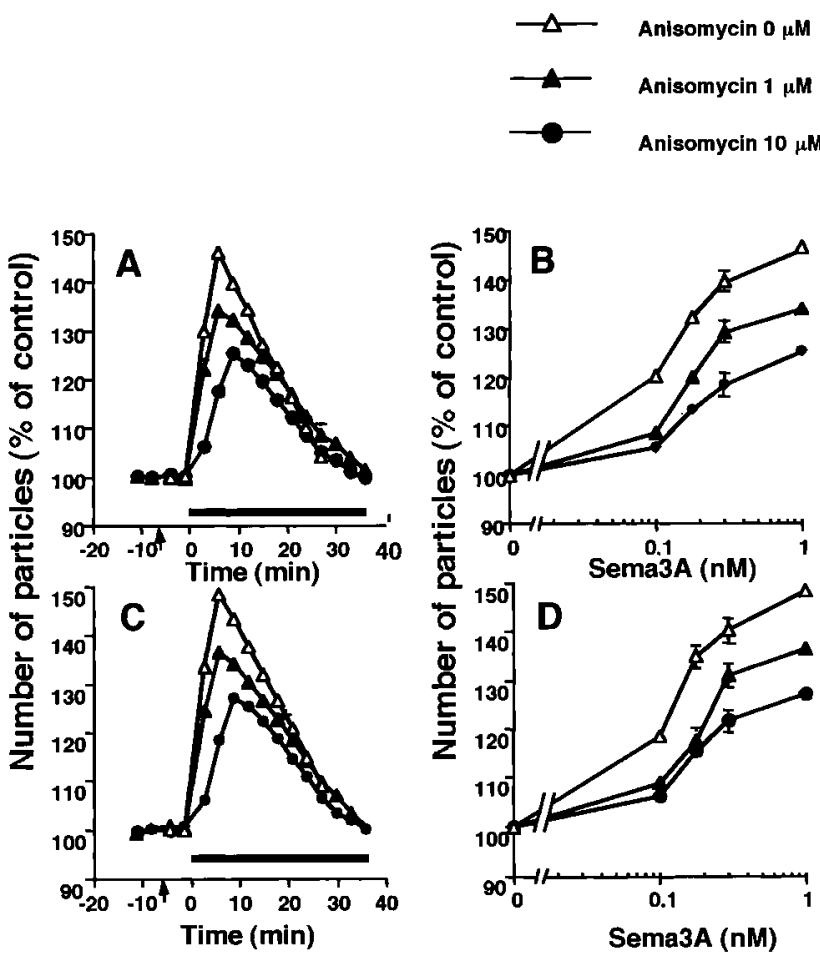

Figure 6. $A-D$, Anisomycin suppressed Sema $3 A$-induced anterograde $(A, B)$ and retrograde $(C, D)$ axonal transport in dissociated mouse DRG neurons. The concentration-response curves for Sema3A on anterograde $(B)$ and retrograde $(D)$ axonal transport in the presence of anisomycin are shown. Anisomycin was applied $7 \mathrm{~min}$ before Sema3A. Ordinates show the percentage of control in the number of moving particles calculated from the average of the two values before application of anisomycin. Data shown are mean $\pm \operatorname{SEM}(n=5)$. Horizontal axes show the time after Sema3A 5 nм application $(A, C)$.

(Fig. $6 B, D$ ). This indicates that the $\mathrm{EC}_{50}$ value for Sema3Ainduced axonal transport was almost identical to that for Sema3A-induced growth cone collapse (Fig. 5A). Anisomycin at the concentrations tested did not affect basal levels of anterograde and retrograde axonal transport. Anisomycin concentration dependently inhibited Sema3A-induced anterograde and retrograde axonal transport, suppressing the maximal effects (Fig. 6).

It has been shown that netrin-1 and lysophosphatidic acid but not Sema3A-induced turning responses are sensitive to LnLL, a cell permeant proteasome inhibitor (Pagano et al., 1995; Campbell and Holt, 2001). We found that LnLL (50 $\mu \mathrm{M})$ showed no effect on Sema3A (0.1 nM)-induced axonal transport as well as growth cone collapse (data not shown). Because LnLL at the concentration of $50 \mu \mathrm{M}$ effectively blocks netrin-1-induced turning response in Xenopus retinal neurons (Campbell and Holt, 2001), it is unlikely that proteasome-mediated protein degradation is involved in the Sema3A-induced axonal transport and growth cone collapse.

\section{Sema3A induces axonal transport in isolated axons}

Protein synthesis responsible for Sema3A-induced axonal transport may be performed locally in the neurite and growth cone. To test this hypothesis, we examined the effects of Sema3A in isolated neurites prepared from dissociated DRG neurons.

The axons and cell bodies of DRG were separated after a $48 \mathrm{hr}$ period of culture. After displacing the culture medium with normal PSS medium for video recording, there appeared to be no differences in growth cone morphology between the intact and isolated growth cone. In contrast, almost every moving particle 

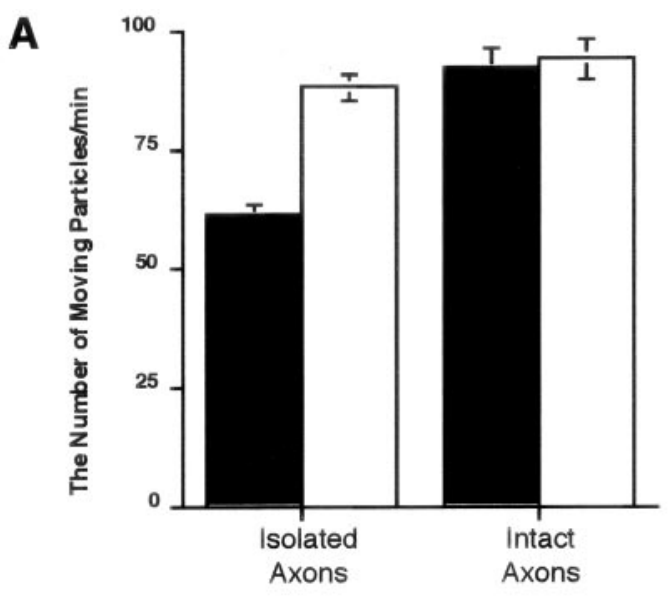

B
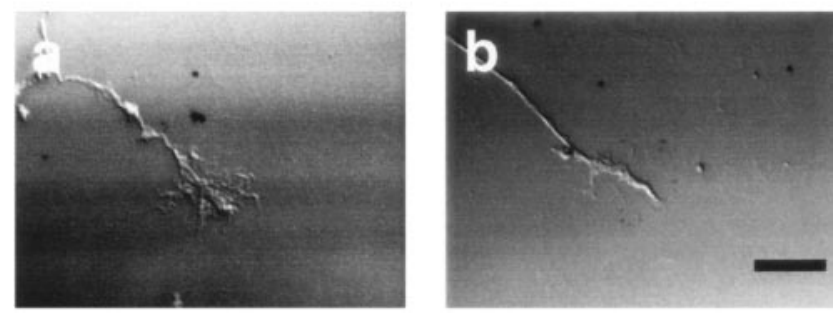

Figure 7. $A, B$, The basal level of axonal transport $(A)$ and growth cone morphology $(B)$ with (b) and without (a) Sema3A (1 nM) of isolated axons. $A$, The number of anterograde (closed column) and retrograde (open column) moving particles (per minute) in the isolated axons 30 min after removal of the cell body. The number of moving particles on anterograde axonal transport was significantly decreased in the isolated axons when compared with that in intact neurons. $B$, Sema3A-induced collapse of isolated growth cones. Data shown are mean \pm SEM $(n=25)$. Scale bar $(B), 10 \mu \mathrm{m}$.

became stationary in the isolated axons a few minutes after the soma was taken off. In an attempt to do analysis of axonal transport in the isolated axons, we used L- 15 medium containing 25 mM glucose. In this medium, the basal levels of anterograde and retrograde moving particles in the isolated axons were recovered within $30 \mathrm{~min}$ and thereafter became stable for at least $3 \mathrm{hr}$ after the isolation.

In the isolated axons, the basal number of anterograde moving particles was $\sim 68 \%$ of retrograde moving particles. The rate of anterograde axonal transport in the isolated axons was significantly smaller than that in the intact ones (Fig. 7A). This might, in part, reflect disruption of the anterograde transport from the cell body after the isolation. However, the growth cones of isolated axons responded to Sema3A to change their morphology, and the acceleration of the transport was seen in a manner similar to that of intact neurons (Figs. $7 B, 8 B-E$ ). This augmentation began within $3 \mathrm{~min}$ and reached a peak value within $6 \mathrm{~min}$ in both isolated and intact axons.

Lavendustin A, olomoucine, and anisomycin suppress Sema3A-induced axonal transport in intact and isolated axons

We next tested the effects of the kinase inhibitors and anisomycin on Sema3A-induced axonal transport in intact and isolated DRG neurons. Lavendustin A, olomoucine, or ansiomycin alone produced no effect on basal axonal transport in the isolated or intact neurons (data not shown). Lavendustin A $(10 \mu \mathrm{M})$ inhibited Sema3A (1 nM)-induced peak increases in anterograde and retrograde axonal transport in intact neurons by 92 and $89 \%$, re-
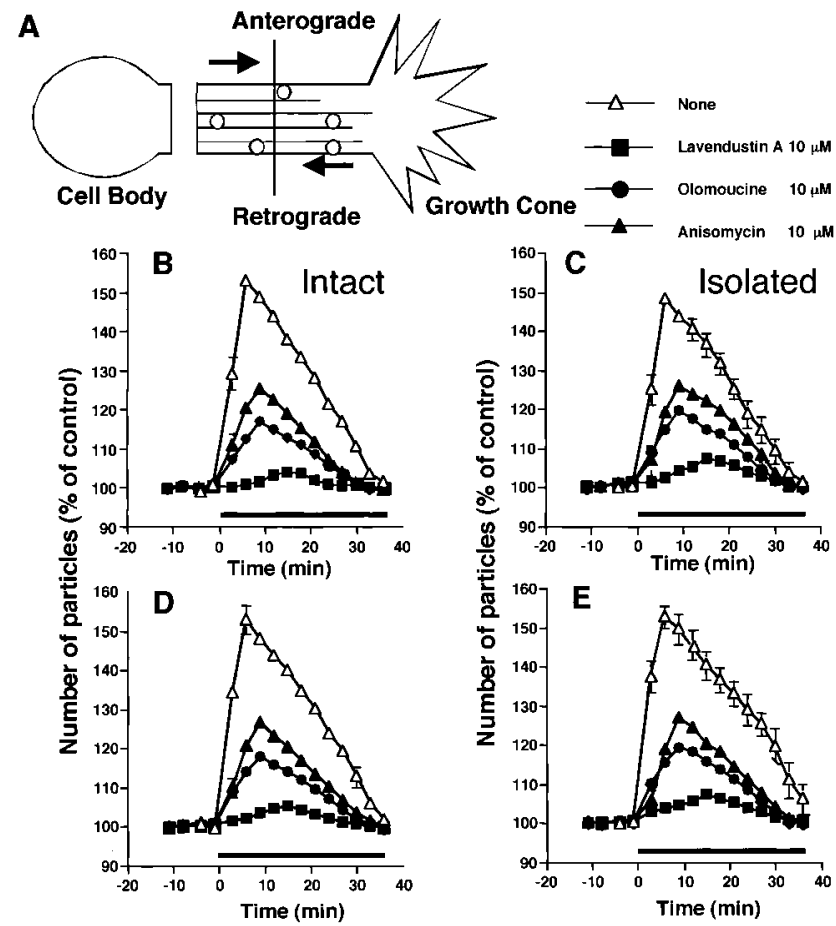

Figure 8. A, A schematic diagram for analysis of axonal transport in isolated axons. The number of moving particles per minute was counted as in intact axons (Fig. 1). $B-E$, Lavendustin $A$, olomoucine, and anisomycin suppressed $S e m a 3 A$-induced axonal transport in intact $(B, D)$ and isolated $(C, E) D R G$ neurons from adult mouse. Sema3A-induced facilitation of anterograde $(B, C)$ and retrograde $(D, E)$ axonal transport in the intact axons and isolated neurons. Lavendustin $\mathrm{A}(10 \mu \mathrm{M})$, olomoucine $(10 \mu \mathrm{M})$, or anisomycin $(10 \mu \mathrm{M})$ was applied 7 min before Sema3A (1 nm). Sema3A was applied at 0 min and thereafter present throughout the experiments (horizontal bar). Data shown are mean $\pm \operatorname{SEM}(n=5)$.

spectively (Fig. $8 B, D)$. In isolated axons, lavendustin A (10 $\mu \mathrm{M})$ inhibited Sema3A-induced increases in anterograde and retrograde axonal transport by 84 and $86 \%$, respectively (Fig. $8 C, E$ ). Likewise, olomoucine $(10 \mu \mathrm{M})$ inhibited Sema3A (1 nM)-induced peak increases in anterograde and retrograde axonal transport in intact neurons by 70.5 and $64.2 \%$, respectively (Fig. $8 B, D$ ). In isolated axons, olomoucine $(10 \mu \mathrm{M})$ inhibited Sema3A-induced increases in anterograde and retrograde axonal transport by 60 and $63 \%$, respectively. In intact neurons, anisomycin at $10 \mu \mathrm{M}$ inhibited Sema3A-induced peak increases in anterograde and retrograde axonal transport by 52 and $49 \%$, whereas in isolated axons, anisomycin $(10 \mu \mathrm{M})$ inhibited the peak increases in the anterograde and retrograde axonal transport by 56 and $50 \%$, respectively. Therefore, the extent to which lavendustin A, olomoucine, or anisomycin inhibited Sema3A-induced anterograde and retrograde axonal transport in the isolated neurons was almost identical to that seen in the intact neurons. These findings suggest that activation of local signaling cascades and local protein synthesis are responsible for Sema3A-induced axonal transport.

Fyn and Cdk5 mediate sema3A-induced activation of a translation initiation factor eIF-4E in local growth cones Detection by a specific antibody against phospho-eIF-4E, the activated form eIF-4E, provides a good monitoring system for local protein synthesis in growth cones (Minich et al., 1994; Gingras et al., 1999; Campbell and Holt, 2001). To get insight into whether Fyn and Cdk5 are involved in Sema3A-induced activation of protein synthesis in local growth cones, we monitored the level of the phosphorylated form of eIF-4E in the growth cones. Sema3A at 
0.1 and $1 \mathrm{nM}$ concentration dependently increased immunofluorescence intensity detected by anti-phospho-eIF-4E (Ser209) antibody in local growth cones (Fig. 9), an observation consistent with those previously made by Campbell and Holt (2001). The levels of intensity in the growth cones rapidly rose and reached a plateau within $5 \mathrm{~min}$ after the addition of Sema3A, the time course of which was similar to that of increase in the axonal transport (Figs. 1, 9A). The immunofluorescence signals were observed in the growth cones, some of which were detected in axonal shafts as well. We monitored total levels of eIF-4E with anti-eIF-4E antibody that recognizes both phosphorylated and nonphosphorylated forms of eIF-4E. There appeared to be no change in fluorescence intensity of the growth cones before and after Sema3A (data not shown). These results suggest that Sema3A increased the level of phosphorylated form of eIF-4E but did not increase the total level of eIF-4E in the growth cones. In this system, both lavendustin A and olomoucine at $10 \mu \mathrm{M}$ significantly repressed the Sema3A ( $0.1 \mathrm{nM})$-induced increases in the immunofluorescence intensity in the growth cones (Figs. $9 B, 10 A, B)$. Lavendustin A or olomoucine at $10 \mu \mathrm{M}$ alone did not affect the intensity of immunofluorescence compared with vehicle controls. These results suggest that lavendustin A-sensitive tyrosine kinase(s) and olomoucine-sensitive cyclin-dependent kinase(s) are involved in Sema3A-induced protein synthesis in the growth cones. We next examined the effect of Sema3A on activation of eIF-4E in the growth cones of $f y n$ - and $p 35$-deficient mouse DRG. The levels of intensity augmented by Sema3A were considerably low in $f y n^{-1-}, f y n^{+/-}$, and $p 35^{-1-}$ when compared with those in wild-type DRG neurons (Fig. 10A-C). Sema3A facilitated axonal transport to a similar extent in wild-type and $f y n^{+/-}$DRG (Fig. 3), although activation of eIF4E appeared to be quite low in both $f y n^{-/-}$and $f y n^{+/-}$DRGs when compared with the wild-type (Fig. 10B).

\section{Discussion}

Local protein synthesis occurs in neuronal cells, and this plays key roles in brain development, neural regeneration, synaptic plasticity, and higher brain functions such as learning and memory (Davis et al., 1992; Torre and Steward, 1992; Kang and Schuman, 1996; Casadio et al., 1999; Martin et al., 2000; Wells et al., 2000; Job and Eberwine, 2001; Zheng et al., 2001; Brittis et al., 2002; Steward and Schuman, 2003). We investigated the relationship between fast axonal transport and local translation in mediating a response to a repulsive axon guidance cue Sema3A of mouse DRG growth cones. First, lavendustin A and olomoucine, both of which suppressed Sema3A-induced growth cone collapse (Sasaki et al., 2002), also inhibited the increase in axonal transport and local activation of eIF-4E translation initiation factor. The effects of Sema3A and the inhibitors of tyrosine kinase(s) and cyclindependent kinase(s) were seen even in the isolated growth cones. This suggests that local signaling in growth cones triggers two kinds of responses, growth cone collapse and axonal transport. Second, Sema3A-induced augmentation of axonal transport and activation of the translation initiation factor were both markedly attenuated in $f y n^{-1-}$ and $p 35^{-1-}$ DRG neurons. Finally, inhibition of protein synthesis suppressed Sema3A-induced anterograde and retrograde axonal transport in isolated and intact axons. Together, our study provides evidence that the Sema3Ainduced facilitation of axonal transport shares the signal transduction cascade with growth cone collapse, and that the close relationship between local protein synthesis and axonal transport exists, implying a physiological relevance of axonal transport triggered by the external guidance cue presented during
A

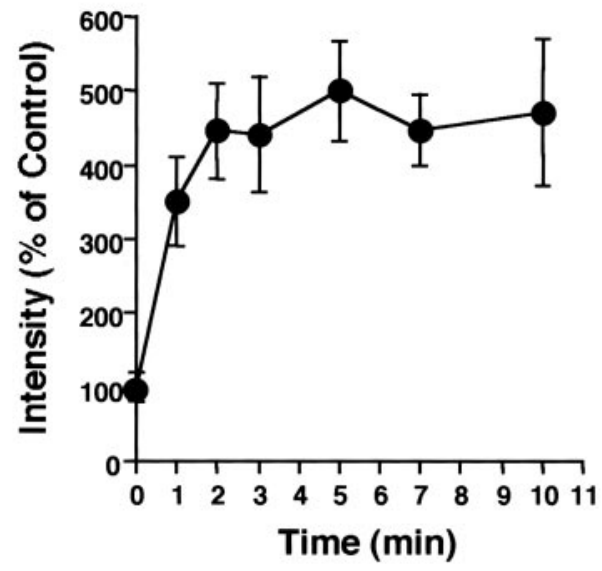

B
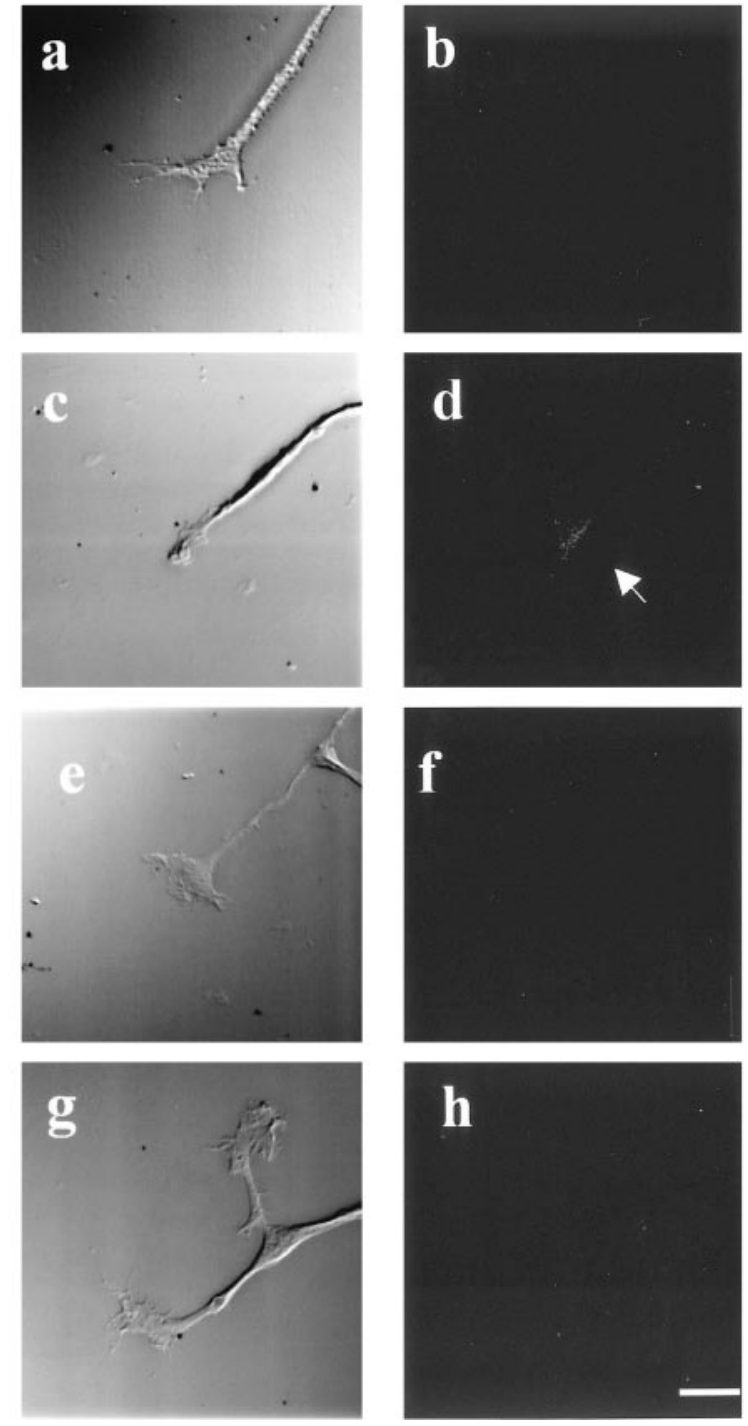

Figure 9. Sema3A-induced activation of a translation initiation factor of elF-4E in the growth cones of DRG explants was blocked by tyrosine kinase and cyclin-dependent kinase inhibitors. $A$, Time course of enhancement by Sema $3 \mathrm{~A}(0.1 \mathrm{~nm})$ applied at 0 min of immunofluorescence intensity detected by anti-phospho-elF-4E in the growth cones. B, Lavendustin A 10 $\mu \mathrm{m}(e, f)$ and olomoucine $10 \mu \mathrm{m}(g, h)$ blocked increase in the immunoreactivies in the growth cones ( $a, c, e, g, \mathrm{DIC}$ image; $b, d, f, h$, anti-phospho-elF-4E immunofluorescence) in response to 5 min treatment with Sema $3 A 0.1 \mathrm{~nm}(c, d)$. Note that Sema3A increased the intensity of immunofluorescence in a punctate manner in the growth cones. Scale bar, $10 \mu \mathrm{m}$. 

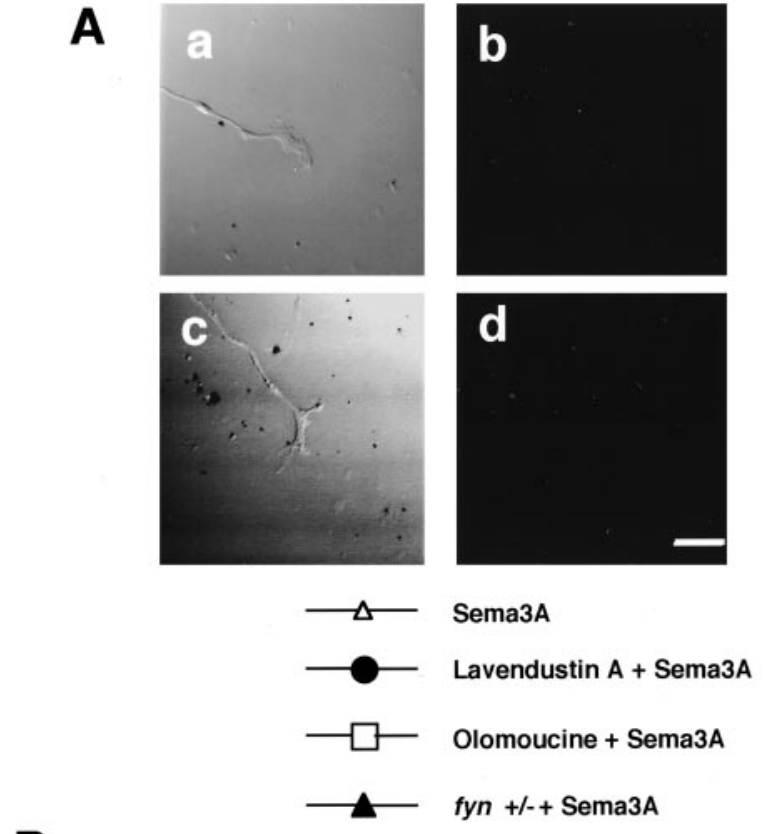

B
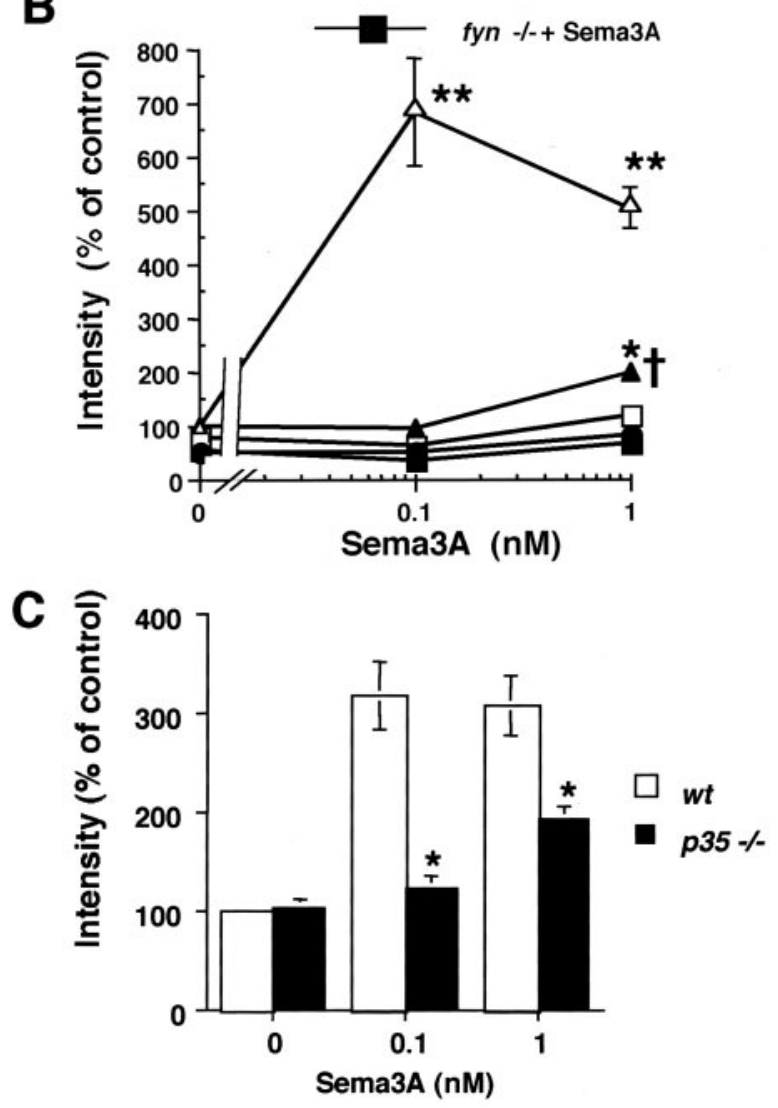

Figure 10. Sema3A-induced activation of elF-4E in the growth cones was suppressed in fyn $^{-1-}$ and $p 35^{-1-}$ DRG explants. $A$, Immunofluorescence images of the growth cones of fyn $^{+1-}(a, b)$ and fyn ${ }^{-1-}(c, d)$ mouse DRG $(a, c$, DIC image; $b, d$, anti-phospho-elF-4E immunofluorescence) in response to 5 min treatment with Sema3A (0.1 nM). Scale bar, $10 \mu \mathrm{m}$. $B$, Quantitative analysis of Sema3A-induced increase in immunofluorescence intensity with the anti-phospho-elF-4E antibody in the growth cones of wild-type, fyn ${ }^{+/-}$, and fyn ${ }^{-1-}$ mouse DRG neurons. Ordinates show mean \pm SEM for the immunofluorescence intensity of phosphoelF-4E/area of each growth cone calculated from 15 growth cones. ${ }^{*} p<0.01$, ${ }^{* *} p<0.001$, compared with corresponding control DRG without Sema 3 A. ${ }^{\dagger} p<0.001$, compared with Sema3A (1 nm) alone in wild-type DRG (open triangle) at the corresponding concentrations. C, Suppression of Sema3A-induced increase in immunofluorescence intensity with the anti-phospho-elF-4E antibody in $p 35^{-1-}$ DRG $(n=30){ }^{*} p<0.05$, compared with wild-type (wt) DRG. development for proper wiring and navigation of neurite extension. Our findings are consistent with a rapid activation of local protein synthesis in growth cones, which is independent of the presence or absence of the cell body (Campbell and Holt, 2001; Brittis et al., 2002; Ming et al., 2002).

\section{Fyn and Cdk5 mediate Sema3A-induced axonal transport}

In addition to a potent inhibition by lavendustin A, Sema3Ainduced anterograde and retrograde axonal transport were markedly attenuated in $\mathrm{fyn}^{-/-}$DRG neurons. Similarly, the growth cone collapse response to Sema3A is inhibited by lavendustin A and is impaired in embryonic DRG neurons of $\mathrm{fyn}^{-1-}$ mice (Sasaki et al., 2002). These findings demonstrate that Fyn tyrosine kinase is involved in both growth cone collapse and increased axonal transport elicited by Sema3A. However, the basal axonal transport was not affected in $f y n^{-1-}$ DRG, and lavendustin A alone did not affect the basal number of anterograde and retrograde axonal transport. This implies that Fyn tyrosine kinase is a regulator for axonal transport elicited by an extracellular signal of Sema3A but not for constant basal axonal transport.

The inhibition by olomoucine of Sema3A-induced axonal transport in the present study is consistent with several lines of evidence indicating that Cdk5 is involved in intracellular membrane trafficking and transport (Smith and Tsai, 2002). However, the precise mechanism of Cdk5-mediated regulation of axonal transport still remains unclear, especially in terms of how Cdk5 regulates both anterograde and retrograde transport. For example, a low concentration of olomoucine $(5 \mu \mathrm{M})$ specific for Cdks inhibits only anterograde transport, whereas higher concentrations $(50 \mu \mathrm{M})$, which are able to inhibit other kinases, inhibit both anterograde and retrograde transport (Ratner et al., 1998). In the present study, we show that Sema3A-elicited anterograde and retrograde axonal transport were selectively inhibited by olomoucine and were suppressed in $p 35^{-/-}$DRG. This finding clearly indicates that Cdk5 is involved in Sema3A-induced bidirectional axonal transport. Cdk5 activity has recently been linked to a motor for the retrograde transport, cytoplasmic dynein, through its ability to phosphorylate a dynein-interacting protein called NUDEL (Niethammer et al., 2000). Regulation of bidirectional axonal transport may also involve phosphorylation of cytoskeletal proteins (Hirokawa, 1999). Sema3A induces phosphorylation of tau by Cdk5 through the active state of Fyn (Sasaki et al., 2002). Tau is a microtubule associated protein and might play an important role in organizing the microtubule cytoskeleton and regulating axonal transport. Overexpression of tau does not alter the speed of moving vesicles but affects the frequencies of attachment and detachment to the microtubule tracks of fluorescence-tagged vesicle and mitochondria. Tau decreases the run lengths both for plus-end and minus-end directed motion to an equal extent (Trinczek et al., 1999). Meanwhile, phosphorylation of tau by Cdk5 reduces the ability of tau to bind to microtubules (Takahashi et al., 2003) and destabilize microtubules (Lew and Wang, 1995). It is thus possible that the phosphorylation of tau inversely facilitates the anterograde and retrograde axonal transport.

\section{Fyn and Cdk5 mediate Sema3A-induced activation of} translation initiation factor

Sema3A increased the level of the phosphorylated form of a translation initiation factor eIF-4E without changing the total level of eIF-4E in growth cones. The increase in the phosphorylated form of eIF-4E by Sema3A was inhibited by lavendustin A and was attenuated in the growth cone of $f y^{-1-}$ DRG neurons. 
We recently found that pyramidal neurons in the layer $\mathrm{V}$ cerebral cortex in adult $f y n^{-/-}$mice show aberrant apical and basal dendrite projections, and this phenotype is quite similar to that of sema3 $A^{-1-}$ mice (Sasaki et al., 2002). Some neurons with multiple dendritic processes do not have polarity, being polygonal rather than pyramidal in shape. The sema3A gene shows strong interaction with $f y n$ on this phenotype. It is thus an intriguing issue whether or not Sema3A-induced axonal transport and local protein synthesis have some relevance in establishing appropriate neurite projection and polarity of layer $\mathrm{V}$ pyramidal cells.

Sema3A-induced activation of eIF-4E in growth cones was also suppressed by olomoucine and showed a lower level in p35 $5^{-/-}$when compared with wild-type DRG. Together, these findings indicate that the activation of the translation initiation factor is a downstream event of the intracellular cascade for Sema3A mediated by Fyn and Cdk5. The mechanisms by which Fyn and Cdk5 mediate Sema3A-induced phosphorylation of eIF-4E (Gingras et al., 1999) and the molecules downstream of these kinases have yet to be determined. Recently, it has been shown that p42/p44 MAPK is activated by Sema3A (Campbell and Holt, 2003). As has been shown in non-neuronal cell system, p42/p44 MAPK-dependent signaling could be triggered by ShcGrb2-Sos formation through activation of Src type tyrosine kinase (Dilworth et al., 1994). Our preliminary study, however, shows that PD98059, a MEK1 inhibitor, at $10 \mu \mathrm{M}$ failed to affect Sema3A-induced axonal transport (data not shown). PD98059 acts as an inhibitor of a p42/44 MAPK by inhibiting MEK1 and consequent phosphorylation of $\mathrm{p} 42 / 44$. Additional study is needed to delineate the relationship between Fyn/Cdk5 and eIF-4E phosphorylation in the Sema3A-signaling cascade.

\section{Local protein synthesis is involved in Sema3A-induced axonal transport}

The peak effect and time course of Sema3A-induced axonal transport in isolated axons were comparable with those seen with intact neurons. Anisomycin suppressed to the same extent the facilitated axonal transport in both intact and severed neurons. These findings indicate that local protein synthesis in growth cones mediates Sema3A-induced axonal transport. Sema3A enhanced the level of immunoreactivity of phosphorylated eIF-4E within 5 min in growth cone in a time course similar to that of the facilitated axonal transport. However, it is an unsettled issue whether or not the local protein synthesis is involved in the initial response or the resensitization phase of the adaptation response or both. In Xenopus retinal neurons, Sema3A-induced rapid chemorepulsive response is blocked by protein synthesis inhibitors (Campbell and Holt, 2003). In contrast, in Xenopus spinal neurons, application of protein synthesis inhibitors for the first 60 min completely abolished resensitization of the turning response when tested at 90 min after bath application of netrin-1 (Ming et al., 2002).

The kinase inhibitors, especially lavendustin A, were more effective than anisomycin in both the isolated axons and intact neurons. This suggests that Fyn and Cdk5 were regulating anterograde and retrograde axonal transport by protein synthesisdependent and protein synthesis-independent mechanisms. The Sema3A-dependent phosphorylation of eIF4E in fyn-deficient mice similarly argues for this idea. Activation of eIF4E was quite similar in the $f y n^{-/-}$and $f y n^{+/-}$DRGs. In contrast, Sema3Ainduced axonal transport was clearly distinct between the $f y n^{-/-}$ and $f y n^{+/-}$axons.

Recent studies demonstrate that intracellular transport of RNA plays a pivotal role in regulating local protein synthesis
(Bassell et al., 1998; Koenig et al., 2000; Zheng et al., 2001, Aronov et al., 2002). It might be plausible to speculate that some of the particle movement elicited by Sema3A represents RNA microtubule-dependent translocation with mRNA-containing granules and clusters of ribosome-like particles, which leads to local protein synthesis in growth cones and axons. Although newly synthesized proteins are unknown, these may be involved in axonal transport as well as growth cone collapse. The candidate proteins and mRNA transported may include receptors, motor proteins, their regulatory mediators, and cytoskeletal proteins. It is interesting to note that tau mRNA is transported via interaction of 3' untranslated region cis-acting signals to $\mathrm{HuD}$, an RNA binding protein, and KIF3A, a member of the kinesin microtubuleassociated motor protein family (Aronov et al., 2001, 2002).

Our present study indicates that local protein synthesis is involved in mediating responses to Sema3A. This is reinforced by our previous observation that local application of Sema3A to growth cone, but to neither neurite nor cell body, promotes axonal transport (Goshima et al., 1999). It is therefore tempting to speculate that Sema3A might elicit retrograde signaling to cell body by accelerating axonal transport to exert its functions. Recently, importin/karyopherin $\alpha$ and $\beta$ families have been reported to underlie retrograde signaling in injured nerve (Hanz et al., 2003). Importin $\beta$ protein is increased after nerve lesion by local translation of axonal mRNA. This leads to formation of a high-affinity nuclear localization signals (NLS) binding complex that traffics retrogradely with the motor protein dynein. Trituration of synthetic NLS peptide at the injury site of axotomized DRG neurons delays their regenerative outgrowth, and NLS introduction to sciatic nerve concomitantly with a crush injury suppresses the conditioning lesion-induced transition from arborizing to elongating growth in L4/L5 DRG neurons. These findings suggest that a lesion-induced upregulation of axonal importin $\beta$ may enable retrograde transport of signals that modulate the regeneratinon of injured neurons. Our present results provide additional evidence for a link between axonal protein synthesis and axonal transport.

The correlation between Sema3A-induced axonal transport and local protein synthesis suggests that a mutual regulatory mechanism between these events in response to axon guidance cues exists. Our observations may serve as a mechanism controlling growth cone sensitivity, desensitization, and upregulated protein expression of distal axon segments (Brittis et al., 2002; Ming et al., 2002). Additional work is necessary to delineate the signaling mechanisms for local protein synthesis and axonal transport and their physiological relevance in axon guidance and neural plasticity.

\section{References}

Aizawa H, Wakatsuki S, Ishii A, Moriyama K, Sasaki Y, Ohashi K, SekineAizawa Y, Sehara-Fujisawa A, Mizuno K, Goshima Y, Yahara I (2001) Phosphorylation of cofilin by LIM-kinase is necessary for semaphorin 3A-induced growth cone collapse. Nat Neurosci 4:367-373.

Aronov S, Aranda G, Behar L, Ginzburg I (2001) Axonal tau mRNA localization coincides with tau protein in living neuronal cells and depends on axonal targeting signal. J Neurosci 21:6577-6587.

Aronov S, Aranda G, Behar L, Ginzburg I (2002) Visualization of translated tau protein in the axons of neuronal P19 cells and characterization of tau RNP granules. J Cell Sci 115:3817-3827.

Bassell GJ, Zhang H, Byrd AL, Femino AM, Singer RH, Taneja KL, Lifshitz LM, Herman IM, Kosik KS (1998) Sorting of $\beta$-actin mRNA and protein to neurites and growth cones in culture. J Neurosci 18:251-265.

Brittis PA, Lu Q, Flanagan JG (2002) Axonal protein synthesis provides a mechanism for localized regulation at an intermediate target. Cell 110:223-235. 
Campbell DS, Holt CE (2001) Chemotropic responses of retinal growth cones mediated by rapid local protein synthesis and degradation. Neuron 32:1013-1026.

Campbell DS, Holt CE (2003) Apoptotic pathway and MAPKs differentially regulate chemotropic responses of retinal growth cones. Neuron 37:939-952.

Casadio A, Martin KC, Giustetto M, Zhu H, Chen M, Bartsch D, Bailey CH, Kandel ER (1999) A transient, neuron-wide form of CREB-mediated long-term facilitation can be stabilized at specific synapses by local protein synthesis. Cell 99:221-237.

Cheng Q, Sasaki Y, Shoji M, Sugiyama Y, Tanaka H, Nakayama T, Mizuki N, Nakamura F, Takei K, Goshima Y (2003) Cdk5/p35 and Rho-kinase mediate ephrin-A5-induced signaling in retinal ganglion cells. Mol Cell Neurosci 24:632-645.

Davis L, Dou P, DeWit M, Kater SB (1992) Protein synthesis within neuronal growth cones. J Neurosci 12:4867-4877.

Dilworth SM, Brewster CE, Jones MD, Lanfrancone L, Pelicci G, Pelicci PG (1994) Transformation by polyoma virus middle T-antigen involves the binding and tyrosine phosphorylation of Shc. Nature 367:87-90.

Gallo G, Letourneau P (2002) Axon guidance: proteins turnover in turning growth cones. Curr Biol 12:R560-R562.

Gingras AC, Raught B, Sonenberg N (1999) eIF4 initiation factors: effectors of mRNA recruitment to ribosomes and regulators of translation. Annu Rev Biochem 68:913-963.

Goshima Y, Kawakami T, Hori H, Sugiyama Y, Takasawa S, Hashimoto Y, Kagoshima-Maezono M, Takenaka T, Misu Y, Strittmatter SM (1997) A novel action of collapsin: collapsin-1 increases antero- and retrograde axonal transport independently of growth cone collapse. J Neurobiol 33:316-328.

Goshima Y, Hori H, Sasaki Y, Yang T, Kagoshima-Maezono M, Li C, Takenaka T, Nakamura F, Takahashi T, Strittmatter SM, Misu Y, Kawakami T (1999) Growth cone neuropilin-1 mediates collapsin-1/Sema III facilitation of antero- and retrograde axoplasmic transport. J Neurobiol 39:579-589.

Goshima Y, Ito T, Sasaki Y, Nakamura F (2002) Semaphorins as signals for cell repulsion and invasion. J Clin Invest 109:993-998.

Hanz S, Perlson E, Willis D, Zheng JQ, Massarwa R, Huerta JJ, Koltzenburg M, Kohler M, van-Minnen J, Twiss JL, Fainzilber M (2003) Axoplasmic importins enable retrograde injury signaling in lesioned nerve. Neuron 40:1095-1104.

Hirokawa (1999) Kinesin and dynein superfamily proteins and the mechanism of organelle transport. Science 279:519-526.

Job C, Eberwine J (2001) Localization and translation of mRNA in dendrites and axons. Nat Rev Neurosci 2:889-898.

Kang H, Schuman EM (1996) A requirement for local protein synthesis in neurotrophin-induced hippocampal synaptic plasticity. Science 273:1402-1406.

Koenig E, Martin R, Titmus M, Sotelo-Silveira JR (2000) Cryptic peripheral ribosomal domains distributed intermittently along mammalian myelinated axons. J Neurosci 20:8390-8400.

Lew J, Wang JH (1995) Neuronal cdc2-like kinase. Trends Biochem Sci 20:33-37.

Martin KC, Barad M, Kandel ER (2000) Local protein synthesis and its role in synapse-specific plasticity. Curr Opin Neurobiol 10:587-592.

Meijer L, Borgne A, Mulner O, Chong JP, Blow JJ, Inagaki N, Inagaki M, Delcros JG, Moulinoux JP (1997) Biochemical and cellular effects of roscovitine, a potent and selective inhibitor of the cyclin-dependent kinases cdc2, cdk2 and cdk5. Eur J Biochem 243:527-536.

Ming GL, Wong ST, Henley J, Yuan XB, Song HJ, Spitzer NC, Poo MM (2002) Adaptation in the chemotactic guidance of nerve growth cones. Nature 417:411-418.
Minich WB, Balasta ML, Goss DJ, Rhoads RE (1994) Chromatographic resolution of in vivo phosphorylated and nonphosphorylated eukaryotic translation initiation factor eIF-4E: increased cap affinity of the phosphorylated form. Proc Natl Acad Sci USA 91:7668-7672.

Nakamura F, Tanaka M, Takahashi T, Kalb RG, Strittmatter SM (1998) Neuropilin-1 extracellular domains mediate semaphorin D/III-induced growth cone collapse. Neuron 21:1093-1100.

Niethammer M, Smith DS, Ayala R, Peng J, Ko J, Lee MS, Morabito M, Tsai LH (2000) NUDEL is a novel Cdk5 substrate that associates with LIS1 and cytoplasmic dynein. Neuron 28:697-711.

Ohshima T, Ward JM, Huh CG, Longenecker G, Veeranna, Pant HC, Brady RO, Martin LJ, Kulkarni AB (1996) Targeted disruption of the cyclindependent kinase 5 gene results in abnormal corticogenesis, neuronal pathology and perinatal death. Proc Natl Acad Sci USA 93:11173-11178.

Ohshima T, Ogawa M, Veeranna, Hirasawa M, Longeneckerm G, Ishigurom K, Pant HC, Brady RO, Kulkarni AB, Mikoshiba K (2001) Synergistic contributions of cyclin-dependant kinase 5/p35 and Reelin/Dab1 to the positioning of cortical neurons in the developing mouse brain. Proc Natl Acad Sci USA 98:2764-2769.

Pagano M, Tam SW, Theodoras AM, Beer-Romero P, Del Sal G, Chau V, Yew PR, Draetta GF, Rolfe M (1995) Role of the ubiquitin-proteasome pathway in regulating abundance of the cyclin-dependent kinase inhibitor p27. Science 269:682-685.

Ratner N, Bloom GS, Brady ST (1998) A role for cyclin-dependent kinase(s) in the modulation of fast anterograde axonal transport: effects defined by olomoucine and the APC tumor suppressor protein. J Neurosci 18:7717-7726.

Sasaki Y, Cheng C, Uchida Y, Nakajima O, Ohshima T, Yagi T, Taniguchi M, Nakayama T, Kishida R, Kudo Y, Ohno S, Nakamura F, Goshima Y (2002) Fyn and Cdk5 mediate Semaphorin-3A signaling, which is involved in regulation of dendrite orientation in cerebral cortex. Neuron 35:907-920.

Smith DS, Tsai LH (2002) Cdk5 behind the wheel: a role in trafficking and transport? Trends Cell Biol 12:28-36.

Steward O, Schuman EM (2003) Compartmentalized synthesis and degradation of proteins in neurons. Neuron 40:347-359.

Takahashi S, Saito T, Hisanaga S, Pant HC, Kulkarni AB (2003) Tau phosphorylation by cyclin-dependent kinase 5/p39 during brain development reduces its affinity for microtubules. J Biol Chem 278:10506-10515.

Tessier-Lavigne M, Goodman CS (1996) The molecular biology of axon guidance. Science 274:1123-1133.

Torre ER, Steward O (1992) Demonstration of local protein synthesis within dendrites using a new cell culture system that permits the isolation of living axons and dendrites from their cell bodies. J Neurosci 12:762-772.

Trinczek B, Ebneth A, Mandelkow E-M, Mandelkow E (1999) Tau regulates the attachment/detachment but not the speed of motors in microtubuledependent transport of single vesicles and organelles. J Cell Sci 112:2355-2367.

Wells DG, Richter JD, Fallon JR (2000) Molecular mechanisms for activityregulated protein synthesis in the synapto-dendritic compartment. Curr Opin Neurobiol 10:132-137.

Yagi T, Aizawa S, Tokunaga T, Shigetani Y, Takeda N, Ikawa Y (1993) A role for Fyn tyrosine kinase in the suckling behaviour of neonatal mice. Nature 366:742-745.

Zheng J-Q, Kelly TK, Chang B, Ryazantsev S, Rajasekaran AK, Martin KC, Twiss JL (2001) A functional role for intra-axonal protein synthesis during axonal regeneration from adult sensory neurons. J Neurosci 21:9291-9303. 